\title{
COMBUSTÍVEL DO TRABALHO DO ATOR: AS DÚVIDAS 1
}

\author{
Andréia Paris ${ }^{2}$ \\ Milton de Andrade (Orientador)
}

RESUMO: O presente texto procura refletir sobre os conceitos deixados ao ator atual, herança de pesquisas do século XX imortalizadas pelos encenadores russos Constatin Stanislavski (1863-1939), Vsévolod Meyerhold (1874-1940) e de certa forma continuadas e repensadas por outros estudiosos como Eugênio Barba (1936). Conceitos estes que elegem o corpo do ator como principal matéria-prima do teatro que, para transformá-lo de matéria em obra de arte, apresentam e problematizam o treinamento, uma possível ferramenta para esculturá-lo.

PALAVRAS-CHAVES: Movimento do Ator; Treinamento; Trabalho do Ator.

\begin{abstract}
Mestre Okura, um famoso professor de kyôgen, uma vez explicou qual a conexão entre o corpo e o palco. Palco, em japonês, se diz butai. A sílaba bu significa "dança" ou "movimento" e tai, "palco". Literalmente, "tablado/lugar da dança". Entretanto, a palavra tai significa também "corpo", o que sugere uma outra possibilidade de leitura: "corpo da dança". Se empregarmos esses sentidos da palavra butai, o que é o artista? Okura dizia que o corpo humano é o "sangue do corpo da dança". Sem isso, o palco está morto. Assim que o artista entra no palco, o espaço começa a ganhar vida; o "corpo da dança" começa a "dançar". Enfim, não é o artista que está "dançando", mas, através de seu movimento, o palco "dança". Nosso trabalho, enquanto atores, não é o de exibir virtuosismo técnico mas, ao contrário, o de fazer com que o palco ganhe vida. (OIDA: 2001, p. 22)
\end{abstract}

...o corpo humano é o "sangue do corpo da dança"... Então, se o corpo humano é o sangue deste corpo que Oida apresenta como espaço, pode ser definido como movimento. O que é o sangue no nosso corpo, se não este movimento líquido e sinuoso em nossas veias, o sopro de vida responsável pela alimentação e respiração de nossas células? O corpo humano é, deste modo,

\footnotetext{
${ }^{1}$ Comunicação apresentada no XVII Congreso Internacional de Teatro Iberoamericano y Argentino, realizado de 5 a 9 de agosto de 2008 em Buenos Aires. Organizado pelo Instituto de Historia del Arte Argentino y Latinoamericano "Luis Ordaz", Facultad de Filosofía y Letras de la Universidad de Buenos Aires.

${ }^{2}$ Aluna regular do PPGT - Mestrado em Teatro/ CEART-UDESC. Ingressa no PPGT em março de 2008, sob orientação do prof. Dr. Milton de Andrade.
} 
sopro e alimento deste outro corpo. Ao movimentar-se para oxigenar e alimentar, o faz dançar, o faz viver, ressuscitar ou despertar. Dilatando suas proporções, suas veias ganham forças e tocam, invisivelmente outros sangues, que não dançam, mas alimentam e oxigenam esse sangue que dança. Alimentam porque assistem o corpo que dança (palco), por meio da dança que o sangue realiza para animá-lo. Um jogo duplo, um ciclo. Assim como a natureza: o ciclo da água, da vida-morte, dia-noite.

Mas que coração bombeia este sangue? De onde vem sua força? Qual pulmão Ihe enche de oxigênio? O que o alimenta dando-Ihe força para dançar e fazer viver aquilo que não tem vida, que não tem alma?

O trabalho do ator parece esbarrar nestas dúvidas, que são sempre feitas e refeitas. Na verdade, o próprio termo, "trabalho do ator" nasceu delas. Termo colocado em pauta no fazer teatral pelos seus principais estudiosos no inicio do século XX. Homens que se despertaram ao ofício do ator porque se fizeram estas questões e construíram suas trajetórias tentando respondê-las. Com esta tarefa nasceu na Rússia o T.A.M. (Teatro de Arte de Moscou), em 1898. Os fundadores, Constantin Stanislavski (1863-1939) e Nemirovtch-Dantchenko (1858-1943), se colocaram esta tarefa e mudaram o teatro no Ocidente. Abriram a "Caixa de Pandora". Estes dois russos deram um corpo ao teatro, que não tinha como cabeça um ator famoso ou uma Diva, mas a unidade de um grupo que deveria ensaiar e preparar a encenação. Rigor que perseguiu a verdade do ator, tentando desenhar sua motivação e neste ímpeto, Stanislavski, aproximadamente na década de dez, traçou um esboço de um método: Linha da intuição e do sentimento. Utilizando, principalmente, a improvisação e jogos teatrais, estimulava seus atores criarem por meio da imaginação, um universo ficcional pautado nas circunstâncias e situações que os autores das peças thes forneciam. (STANISLAVSKI: 1989, p. 307).

Bem longe de se contentar com este modo de trabalhar, Stanislavski, na década de 30, reorganiza todo o seu modo de fazer teatral e nos deixa conceitos que perpetuam no trabalho do ator atual. (RUFFINI (in) JIMENEZ: 1990, p. 189) Destes, ressaltarei: 1. Trabalho do ator sobre si mesmo; 2. Segunda natureza; 3. Ação-psicofísica. O primeiro inicia a discussão de que o ator deveria trabalhar seu material, ou seja, seu corpo, independente de personagem, do drama ou da 
encenação ${ }^{3}$. Insinua, portanto, que o ator tenha uma preparação separada, voltada apenas para sua expressividade, à construção de uma segunda natureza, expressiva, viva, pulsante, extra-cotidiana na ação-psicofísica. Em outras palavras: um trabalho cuja expressividade deveria pautar-se numa única lei: reorganização de sua presença física ( $2^{\circ}$ natureza) em que corpo e mente soa em uníssono (ação-psicofísica). (RUFFINI (in) JIMENEZ: 1990 p. 193).

No entanto, paralelamente ao trabalho de Stanislavski, seu discípulo Vsévolod Meyerhold (1874-1940), com quem trabalhou de 1898 a 1902 e em outros momentos de suas histórias, também carregando os mesmos questionamentos, trilhou caminhos que ora cruzava, ora se distanciava do mestre. Afastava-se porque enquanto Stanislavski trabalhava sob o conceito de criação do ator por meio do estudo da personagem, Meyerhold elaborava a teatralidade de seu teatro em torno da figura do próprio ator. Buscando exemplos em diversas fontes que desenvolviam também estas visões: Gordon Craig (1872-1966), G. Fuch (1868-1932), a Commedia dell'Arte, os atores de rua e de feira russos, o mimo, a pantomima, o Music Hall e o Teatro Oriental, pôde refletir os mecanismos de encenação e principalmente, a preparação do ator ao perceber a movimentação deste como cerne do fazer teatral que idealizava, repensando o conceito de teatralidade. (CARLSON: 1997, p. 310)

Formando várias parcerias com artistas e pensadores das mais diversas áreas, cujas uniões geraram inúmeras pesquisas, escolas e grupos experimentais nos quais desenvolveu suas teorias. Dentre estas parcerias nasceu Teatro da Convenção, juntamente com o pensamento do poeta simbolista russo Valery Briussov (1873-1924), cuja exigência de uma movimentação estilizada, rítmica e marionetizada demonstraram-Ihe a necessidade de pesquisar um treinamento específico para o ator explorar este tipo de expressão. (MEYERHOLD: 1972, p. 141-183) Neste caminho esboça um primeiro treinamento próprio para o ator em parceria com Vladimir N. Solovióv4: uma série de 16 Estudos e pantomimas. Ensinados no Meyerhold Studio (1913), juntamente com outras práticas corporais e vocais, os Estudos (Étude) apresentavam aos estudantes alguns princípios do

\footnotetext{
${ }^{3}$ Embora Stanislavski sempre trabalhasse apoiando-se num texto dramático, serviu de premissa para pesquisas significativas ao fazer teatral atual como o de Jerzy Grotowski (1933-1999) e de Eugênio Barba (1936). (FERRACINI: 2003, p. 66-70)

${ }^{4}$ Especialista em Commedia Dell' Arte e Teatro Espanhol do séc. XVII que ensinava estes conteúdos no Meyerhold Studio (1913).
} 
movimento cênico aos quais Meyerhold ressaltava como fundamentais para a prática de um gesto teatralizado. No inicio da década de vinte, estes Estudos foram transformados a partir de uma reflexão de outras ciências como o Taylorismo $^{5}$, a Reflexologia ${ }^{6}$, os ideais do Movimento Construtivista e do momento social, econômico e político pelo qual a Rússia passava no momento, fazendo parte do treinamento do ator idealizado e denominado por Meyerhold de Biomecânica.

Portanto, com Meyerhold, temos um inicio de treinamento idealizado para o ator, separado de uma encenação, voltado exclusivamente para domínio de seu corpo, controle de sua expressão. Pode ser dito então que, no Ocidente, Meyerhold inaugurou as perguntas: por meio do movimento do sangue (sangue aqui entendido como corpo do ator), posso entender sua dinâmica, seu ritmo, sua textura, seu cheiro, sua cor, seu volume, seus desenhos, seus caminhos? E, ao entender estes princípios, são possíveis chegar ao coração, pulmão, cabeça, alma, o corpo/palco? Poderei soprar-Ihe vida? Inspirar-Ihe amor?

O treinamento nasce com esta promessa. Já não é mais o papel, o personagem que desperta a imaginação do ator e o auxilia na construção do seu trabalho. Seguindo o exemplo de Meyerhold, o movimento seria este novo estimulador da imaginação do ator. O movimento proporciona ao ator estabelecer relações concretas e poéticas de sua presença cênica corporal, a partir das idéias da encenação ou outros estímulos, sendo estas manipuladas ou não pelo diretor, com os objetos de cena, luz, figurino e com as demais presenças em cena (demais atores) e fora dela (espectador). Um meio eficaz, quando bem estruturado e contextualizado, com o qual o ator consegue atravessar toda a distância que há entre a sua idéia, passando pela sua imagem, intenção e energia para comunicá-la ao público.

O treino, deste modo, torna-se este tempo, espaço e material ao qual o ator se dedica para confronta-se com seu corpo, com a sua dinâmica, seu ritmo, sua

\footnotetext{
${ }^{5}$ O Taylorismo foi criado por Frederick Winslow Taylor (1856-1915), americano pioneiro no estudo de administração cientifica. (GORDON: 1973, pg. 73-88)

${ }^{6}$ Pouco antes de 1900, surgiram algumas escolas denominadas de "Psicologia objetiva" que rejeitava "a noção de alma e minimizando (sic) a importância do inconsciente inatingível, os "objetivistas" procuraram outros caminhos para explicar o comportamento". Meyerhold teve acesso a essa teoria pelo estudo do russo Vladimir Bekhterev (1857-1927). (GORDON: 1973, pg. 73-88)
} 
textura, seu cheiro, sua cor, seu volume, seus desenhos, seus caminhos, que nada mais é, se traduzirmos estes elementos para uma linguagem, a qual podese denominar teatral, teremos os princípios pré-expressivos ${ }^{7}$ : energia, corpo extra-cotidiano, equilíbrio/desequilíbrio ${ }^{8}$, dilatação, oposição, omissão, e ritmo.

Prática esta firmada por Eugênio Barba e Grotowski que a exemplo de Stanislavski e Meyerhold, abriram Teatros-Laboratórios ${ }^{9}$ e tornaram-se referencia no ao universo do teatro atual quando o assunto é treinamento do ator.

No seu trabalho, Eugênio Barba (1991, p. 53), quando criou seu grupo em 1964, em Oslo, na Noruega, depois de passar quase três anos trabalhando com Grotowski, introduz o treinamento ao seu grupo utilizando exercícios da pantomima, do balé, da ginástica, do esporte, da ioga, das artes plásticas e com o tempo foi trazendo outros, como do teatro oriental e exercícios da biomecânica de Meyerhold. Treinavam diariamente, com o intuito de dominar o exercício em toda a sua extensão, forma e execução. E com isso, chegar ao coração, às vísceras deste corpo-sangue que é o trabalho do ator.

Contudo, Barba percebeu que as respostas que chegavam depois de anos de trabalho não eram as esperadas. Não despertaram, as vísceras deste corpo, não como acreditavam que o fariam. Vísceras que pode ser traduzida por bios cênicos, corpo em vida termo que Barba traz em seus textos, ou, verdade para Stanislavski. Como pesquisador, Barba não queria apenas percebê-las, mas descrevê-las, revela-las ao grande público. "Durante nossos primeiros anos de trabalho também acreditávamos no "mito da técnica", algo que era possível se adquirir, possuir e que poderia dar ao ator o domínio consciente do seu corpo" (BARBA e SAVARESE: 1995, p. 245). Fato este já alertado por Meyerhold. (ILINSKI (in) CONRAD: 1969, p. 158). Assim, fica claro que o treinamento é muito eficaz, mas é um meio. Mais uma vez, as mesmas dúvidas já colocadas aqui ressoam novamente como um mantra, como uma verdade que não deve se calar.

\footnotetext{
7 Abordados e ressaltados pela Antropologia Teatral : "Antropologia Teatral é o estudo do comportamento do homem, no nível biológico e sociocultural, em uma situação de representação" (BARBA: 1991, p. 189). Disciplina estudada pelo ISTA (International School of the Theatre Antropology), que reúne interessados do mundo todo e gerou o livro A Arte Secreta do Ator: Dicionário de Antropologia Teatral, organizado por Barba e Savarese, editado no Brasil em 1995. ${ }^{8}$ Equilíbrio/desequilíbrio é o que, Na A Arte Secreta do Ator: (1995), os autores, Barba e Savarese chamam de "equilíbrio de luxo".

9 "Teatro-Estúdio" da rua Povarskáia, parceria de Meyerhold e Stanislavski. Primeiro estúdio no qual não havia intenção de montar nada, apenas pesquisar a expressividade do ator. (MEYERHOLD: 1972, p. 124)
} 
O treinamento não ensina a interpretar, a se tornar hábil, não prepara para a criação. O treinamento é um processo de autodefinição, de autodisciplina que se manifesta através de reações físicas. Não é o exercício em si mesmo que conta por exemplo, fazer flexões ou saltos mortais - mas a motivação dada por cada um ao próprio trabalho, uma motivação que, ainda quem banal ou difícil de se explicar por palavras, é fisiologicamente perceptível, evidente para o observador. Essa abordagem, essa motivação pessoal decide 0 sentido do treinamento, da superação dos exercícios particulares, na verdade exercícios ginásticos estereotipados. (BARBA: 1991, p. 59)

Percebe-se que o treinamento deve se aprofundar mais no seu objetivo de desenvolver as capacidades do ator, sua autonomia, sua independência enquanto matéria-prima, objeto de arte, pensador e idealizador do fazer teatral. Não é mais apenas para construir uma linguagem comum de grupo, mas para fazer com que cada membro do grupo pesquise e molde sua individualidade, descubra a sua particularidade, reforce sua identidade e com isso, contribua para a arte do grupo. Assim, cada ator deve ter muito claro o que deve aprimorar e escolhe os exercícios nos quais deve se aprofundar. Aprender dominar para romper, recriar, restabelecer limites, provocar, estimular, defrontar-se com o desconhecido. A disciplina do ator, sua obstinação não deve ter compromisso com os outros, mas exclusivamente consigo mesmo, com sua própria arte. Isto é um passo muito decisivo e forte que, longe de empurrar o ator para frente, dá-lhe um chacoalhão, suspende-o no ar. Dá-lhe uma responsabilidade que antes era destinada ao texto dramático ou à figura do diretor do espetáculo. Evoluir de simples objeto, acessório do teatro, tal como era no século XVIII e XIX, para o status de artista requer muita responsabilidade também.

Contudo, se o treinamento não forma o ator, e se não basta exibir em cena um virtuosismo técnico, para quê o treinamento? E como ficam as questões levantadas no inicio? Como fazer com que o espaço dance por meio de meu corpo? Como encontrar a segunda natureza, à ação psico-física que Stanislavski ressalta? Como ter uma expressão justa, precisa, teatral que Meyerhold invoca? Como desenvolver meu bios cênico? Que coração bombeia este sangue que é 
meu corpo? De onde vem sua força? Qual pulmão lhe enche de oxigênio? O que o alimenta dando-lhe força para dançar e fazer viver aquilo que não tem vida, que não tem alma?

Parece que ninguém tem as respostas. No entanto, todos estes estudiosos aqui citados não nos deixam no escuro. Oferecem-nos, como uma herança rica, as mesmas dúvidas que iniciaram suas trajetórias, que proporcionaram que trabalhassem, que pescassem seus peixes, que os colocassem em auto mar. Outro dado interessante, é o treinamento como a primeira vara, contudo, sabe-se que há outros meios para pescar: a rede, a lança. E por fim, Barba (1991, p. 99) nos traz outro dado importante: "O que importa é o motor. Ás vezes, tem-se boa vontade, mas se carece de força motriz. Esse motor sempre está em nosso interior, nunca em nosso exterior. Não é uma idéia ou uma pessoa". Permito-me fazer uma última pergunta: O que é que me motiva ser atriz?

\section{Referências Bibliográficas :}

BARBA, E.; SAVARESE, N. A Arte Secreta do Ator. Dicionário de Antropologia Teatral. Campinas-SP: HUCITEC, 1995.

1991.

Além das Ilhas Flutuantes. São Paulo - Campinas: HUCITEC,

CARLSON, Marvin. Teorias do Teatro: Estudo Histórico-Crítico, dos Gregos à Atualidade. São Paulo: Fundação Editora da UNESP, 1997.

CONRADO, Aldomar (org) O Teatro de Meyerho/d. Rio de Janeiro: Civilização Brasileira, 1969.

FERRACINI, Renato. A Arte de Não Interpretar Como Poesia Corpórea do Ator. Campinas, SP: UNICAMP, 2003.

GORDON, Mel. "A Biomecânica de Meyerhold" (in) The Drama Review. (T57) março de 1973, pg. 73-88. Tradução de Maria Elizabeth Biscaia Jhin.

GUINSBURG, J. Stanislavski e o teatro de Arte de Moscou: do Realismo Externo ao Tchekhovismo. São Paulo: Perspectiva, 1985.

JIMENEZ, Sérgio. El Evangelio de Stanislavski Según sus Apóstoles, los Apócrifos, la Reforma los Falsos Profetas y Judas Iscarlate. México: Editorial Gaceta, 1990. 
LABAN, Rudolf Von. Domínio do Movimento. São Paulo: Summus, 1978.

MEYERHOLD. Textos Teóricos. Madrid: Alberto Corazon, 1972. 1 V.

OIDA, Yoshi. O Ator Invisível. São Paulo: Beca Produções Culturais, 2001.

STANISLAVSKI, Constantin. Minha Vida na Arte. Rio de Janeiro: Civilização Brasileira, 1989. 